\title{
Lineamientos de Gestión Territorial en la parroquia Carayaca, estado Vargas. Análisis de conflictos de uso de la tierra
}

\author{
Anays Florez Castillo*
}

Recibido el 2 de enero de 2017; aceptado el 15 de junio de 2017

\section{Resumen}

Con el propósito de identificar los conflictos de uso de la tierra en la parroquia Carayaca ubicada en el estado Vargas, en la presente investigación se utilizó la imagen de satélite LANDSAT 8-OLI para la estimación, análisis y cuantificación de los conflictos de uso. El proceso metodológico utilizado integra técnicas de procesamiento digital de imágenes de satélite con análisis espacial de la información temática, lo cual permitió determinar categorías de uso de la tierra y clases de cobertura vegetal. El análisis espacial reveló que la parroquia posee características particulares, aspectos naturales que le otorgan cierta fragilidad ambiental, intervención antrópica y presencia de Áreas Bajo Régimen de Administración Especial, que junto con el incumplimiento del ordenamiento jurídico vigente han propiciado la existencia de conflictos de uso. Se identificaron tres tipos de conflictos: normativos, por pendiente y por erosión, con una superficie de $43 \%$ del área total evaluada. Se concluye con estrategias de uso y manejo que conduzcan a dar soluciones a los conflictos, elevar la calidad de vida de la población, lograr un desarrollo económico sostenible, preservar los recursos naturales y fuentes de energía. Se recomienda el uso de prácticas conservacionistas que controlen la erosión, implementar programas y acciones que tengan por finalidad el ordenamiento territorial, mediante la coordinación, aplicación y supervisión de acciones que coadyuven a la regulación de la ocupación del territorio, aprovechamiento de recursos y la recuperación de áreas

* Universidad Central de Venezuela, Facultad de Humanidades y Educación, Instituto de Geografía y Desarrollo, Los Chaguaramos, 1050, Caracas, Venezuela, correo electrónico: anaysflorez_c@hotmail.com. 
degradadas enmarcado en un proceso de participación y corresponsabilidad ambiental a fin de garantizar una gestión territorial eficiente.

Palabras clave: uso de la tierra, análisis espacial, gestión territorial, erosión de suelo.

\section{Resumo}

Com o propósito de identificar os conflitos de uso da terra na paróquia de Carayaca localizada no estado de Vargas, a presente pesquisa se utilizou de imagens de satélite LANDSAT 8-OLI para a estimação, análises e quantificação dos conflitos de uso. O processo metodológico utilizado integra técnicas de processamento digital de imagens com análise espacial da informação temática, que permitiu determinar categorias de uso da terra e classes de cobertura vegetal. A análise espacial revelou que a paróquia possui características particulares, aspectos naturais que lhe outorgam certa fragilidade ambiental, intervenção antrópica e presença de áreas sob regime de administração especial, que junto com a violação do ordenamento jurídico vigente tem propiciado a existência de conflitos de uso. Identificou-se três tipos de conflitos: normativos, devido a declives e os de erosão, com uma superfície de $43 \%$ da área total avaliada. Se conclui que com estratégias de uso e manejo que conduzam a dar soluções aos conflitos, possa se elevar a qualidade da vida da população, lograr um desenvolvimento econômico sustentável, preservar os recursos naturais e fontes de energia. Se recomenda o uso de práticas conservacionistas que controlem a erosão. Além disso, sugere-se a implementação de programas e ações que tenham por finalidade o ordenamento territorial, mediante a coordenação, aplicação e supervisão de ações que contribuam para a regulação da ocupação do território, aproveitamento de recursos e recuperação de áreas degradadas. Estas áreas deverão estar enquadradas em um processo de participação e corresponsabilidade ambiental a fim de garantir uma gestão territorial eficiente.

Palavras chave: uso da terra, análise espacial, gestão do território, erosão do solo.

\section{Abstract}

In order to identify land use conflicts in Carayaca located in Vargas state, in the following research the LANDSAT 8-OLI satellite image was used for the estimation, analysis and quantification of conflicts of use. The methodological process used integrates techniques of digital processing of satellite images with spatial analysis of thematic information, which allowed to determine categories of land use and types of vegetation cover. The spatial analysis revealed that the space has particular characteristics, natural aspects that give it some environmental fragility, anthropic intervention and presence of Areas Under Special Management Regime, which with the non-compliance of the current legal system have led to the existence of conflicts of use. Three types of conflicts were identified: normative, by slope and 
erosion, with an area of $43 \%$ of the total evaluated area. It concludes with use and management strategies that lead to solve conflicts, raise the quality of life of the population, achieve sustainable economic development, and preserve natural resources and energy sources. It is recommended to use conservation practices that control erosion, implement programs and actions that have the purpose of land-use planning, by coordinating, applying and supervising actions that contribute to the regulation of land-use occupation, resource utilization and recovery of degraded areas framed in a process of participation and environmental co-responsibility in order to ensure efficient land-use management.

Key words: land use, spatial analysis, land-use management, soil erosion

\section{Introducción}

El continuo proceso de ocupación del territorio y la presión por la expansión de la frontera agrícola en la parroquia Carayaca del estado Vargas, se ha desarrollado en un territorio con características naturales restrictivas y frágiles mayormente montañoso, con pronunciadas pendientes, una estrecha faja litoral y la presencia de Áreas Bajo Régimen de Administración Especial (ABRAE) en gran parte de la parroquia, ocupando una superficie estimada de 29087 ha (61\% aproximadamente, respecto a la referida unidad político-territorial).

Dicha parroquia es una de las pocas áreas agrícolas del estado, en donde según el Ministerio del Ambiente y los Recursos Naturales Renovables (MARNR, 1985), la presencia humana a través de diversas actividades en áreas con condiciones frágiles, es decir, la ocupación de áreas físicamente no aptas que propician la transformación de ecosistemas naturales en intervenidos, ésta es parte de la problemática ambiental de la parroquia, en la cual dichos problemas se refieren a sobreutilización y degradación de recursos.

El área posee características particulares por la presencia de cinco ABRAE, que definen usos y restricciones desde el punto de vista legal y ambiental, en los últimos años se han visto afectadas por el avance de las ocupaciones del territorio, producto de invasiones y explotaciones agrícolas, evidenciándose áreas deforestadas en la parte alta de las cuencas. Los conflictos surgen, por una parte, debido a que las invasiones promueven el uso del suelo no acorde con sus potencialidades, y por otra la falta de instrumentos de evaluación, control y monitoreo sobre las ABRAE.

En la parroquia se han detectado innumerables problemas como establecimientos no conformes de viviendas, consolidación de desarrollos agrícolas no controlados, degradación de suelos, y contaminación de aguas por la ausencia de prácticas conservacionistas y uso indiscriminado de biocidas, pesticidas y fertilizantes (Ministerio del Poder Popular para el Ambiente- MPPA, 2011).

Por las razones antes expuestas, es fundamental identificar el uso actual en las áreas con potencialidades y limitantes naturales con miras a definir áreas de conflic- 
tos, entre ellos, conflictos normativos en las ABRAE, considerando que de continuar dicha tendencia a corto plazo se podrá evidenciar un mayor avance de la frontera agrícola en las áreas no aptas y no permitidas según la normativa actual.

En este contexto, se plantea como objetivo formular propuestas de uso y manejo de los recursos a través del análisis de las zonas de conflicto de uso de la tierra, que puedan contribuir con los lineamientos de la gestión territorial en la parroquia Carayaca, estado Vargas.

\section{Procedimiento metodológico}

En primer lugar, se realizó una revisión bibliográfica y cartográfica para cumplir con el objetivo propuesto a fin de obtener los fundamentos teórico-conceptuales sobre el tema, el marco legal y normativo, y el diagnóstico de los subconjuntos físico-natural, socio-económico y político-administrativo.

En segundo lugar, se utilizó la imagen LANDSAT 8- OLI (escena p004 r053) de enero de 2014, la cual fue procesada a través Software Erdas, por medio de técnicas de procesamiento digital en imágenes de satélite junto con el análisis espacial de la información temática a través del software ArcGis 10.2.1. Se aplicaron técnicas de realce y algoritmos (histograma de ecualización), mejoras visuales por medio de composiciones en falso color. Se crearon también imágenes nuevas para extraer información adicional, de este modo se elaboró un Índice de Vegetación de Diferencia Normalizada (NDVI) que minimiza el efecto del suelo y las posibles perturbaciones atmosféricas sobre la vegetación.

Luego de este preprocesamiento de la imagen se definieron categorías teniendo en cuenta las características del área de estudio, estableciendo a priori una leyenda con seis categorías de usos discriminables en la imagen (Bosque Siempreverde, Bosque Semideciduo, Matorral, Uso Agrícola, Sombras, Sin Cobertura Vegetal). Para clasificar la imagen se optó por el método de clasificación no supervisado, por ser el más apropiado para el área de estudio. El algoritmo de clasificación empleado es de tipo paramétrico; se trabajó al 95\% de confiabilidad de la clasificación de la imagen, obteniendo resultados bastante satisfactorios y cercanos a la realidad.

Posteriormente se realizó una verificación en campo, para la identificación de coberturas de suelo y la corroboración de las clases de cobertura resultantes de la clasificación, obteniendo de esta manera el mapa de cobertura y uso actual.

Para la identificación de las zonas de conflicto, se elaboró un Modelo Digital de Elevación (MDE) de la parroquia Carayaca a partir de las curvas de nivel cada 20 metros y a escala 1:100 000 a través del software ArcGis, posteriormente se creó el mapa de pendientes con el Spatial Analyst tools del mismo software. Esto permitió realizar el análisis de tres tipos de conflictos: 
- El análisis de conflictos normativos, se realizó por medio de la superposición entre la capa de ABRAE y áreas de cultivos existentes dentro de dichas áreas, los conflictos se determinaron a través del análisis del incumplimiento de la normativa actual correspondiente a los Decretos de creación, Planes de Ordenación y Reglamentos de Uso, Decreto Nº 276 y la Ley de Aguas (2007).

- Análisis de conflictos por pendiente. Al realizar el análisis de la pendiente y la normativa de suelos establecida en la Ley de Forestal de Suelos y de Aguas (1966) y el Reglamento de la Ley de Forestal de Suelos y de Aguas (1977), se determinaron las áreas de conflicto por pendiente con respecto a las zonas de cultivo que no cumplen con la normativa establecida en dicho reglamento.

- Análisis de conflictos por erosión. Para determinar las áreas susceptibles a erosión se realizó un análisis entre la pendiente del terreno y la proximidad a los ríos (buffer de $300 \mathrm{~m}$ ), correspondiente a la franja establecida como zona protectora de los cuerpos de agua, según la Ley de Aguas. El análisis se realizó mediante el software ArcGis y con la previa reclasificación de los raster obteniendo el mapa de erosión de la parroquia; posteriormente se realizó la superposición de esta capa con las áreas de cultivos y las unidades litológicas, para realizar el análisis con respecto a lo establecido en el Reglamento de la Ley de Forestal de Suelos y de Aguas.

Luego de efectuar el análisis de cada variable considerada para la determinación de conflictos de uso de la tierra, se realizó un mapa síntesis obteniendo como resultado las zonas de conflicto existentes en la parroquia.

Finalmente, se realizó el análisis de los resultados obtenidos tanto en la fase diagnóstico como la fase de análisis de conflictos, con la finalidad de determinar los factores y causas que originan la problemática para posteriormente establecer algunas estrategias como lineamientos de acción para garantizar la administración eficiente y el desarrollo de la parroquia.

\section{Características generales del área de estudio}

\section{Localización}

El área de estudio corresponde con la parroquia Carayaca del estado Vargas, localizada en la vertiente norte de la Serranía del Litoral (Figura 1). Se ubica entre las coordenadas UTM zona 19 N: 673 736,216 y 716 935,794 m E y 1162 643,294 y 1166 320,891 m N. Carayaca es la parroquia más grande del estado Vargas, posee una superficie de 47691 ha, lo cual representa el 31.9\% del área total del estado. Limita por el norte con el Mar Caribe, por el sur con el Distrito Capital y estado Aragua, por el este con la parroquia Catia La Mar y Distrito Capital y por el oeste con el estado Aragua. 


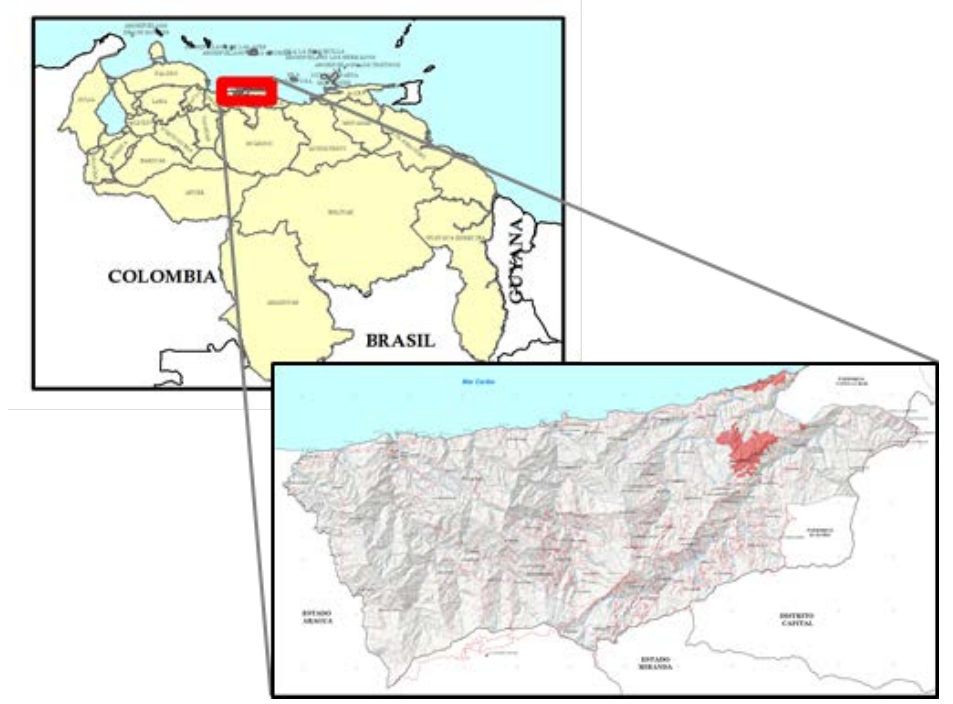

Figura 1. Localización del área de estudio.

\section{Condiciones naturales y uso de la tierra}

Las condiciones físico naturales presentes en el área de estudio están determinadas por su emplazamiento en la Cordillera de la Costa, cuya estructura está definida por el sistema de fallas del Caribe y San Sebastián, en la cual interactúan las tres asociaciones litológicas existentes. El área se encuentra influenciada por fallamientos geológicos antiguos y recientes, los cuales plegaron y modelaron la estructura actual, encontrándose una estructura con actividad tectónica caracterizada por un intenso fracturamiento y meteorización distintivo de la Serranía Litoral; aunado con la topografía abrupta ha propiciado inestabilidad y dinámica de estos materiales en laderas ocasionando raptación, deslizamientos y derrumbes.

Las condiciones climáticas son muy diversas, ya que existe un amplio nivel altitudinal, generando un extenso gradiente altotérmico y cuyas precipitaciones están condicionadas por las características orográficas predominantes que van desde condiciones de humedad semiáridas (corredor costanero), hasta subhúmedo.

Por otra parte, la parroquia cuenta con pocas potencialidades adecuadas para el desarrollo de cultivo dadas las condiciones de suelos existentes, por lo cual la mayor proporción de suelos en la parroquia debe estar sujetos a medidas de conservación, ya que, por poseer pendientes fuertes, son muy proclives a sufrir procesos erosivos intensos.

Como resultado de las condiciones climáticas, de las características de los suelos y la topografía, se presenta un gradiente de vegetación entre el nivel del mar y los 2400 msnm el cual, mantiene un perfil ecológico muy importante representado 
por la biodiversidad de plantas entre bosques siempreverde, bosques nublados y matorrales. El sector mantiene el más alto grado de conservación y equilibrio ecológico de la franja costera del estado Vargas, gracias a las ABRAE que han contribuido a su protección, este grado de conservación ha permitido la supervivencia de atractivos turísticos únicos como el submarinismo y el aprovechamiento de aguas termales.

La mayor proporción de la parroquia posee una configuración territorial con gran analogía, dadas las características rurales existentes y el predominio de la actividad agrícola. Por otra parte, al noroeste y litoral de la cuenca Petaquire por sus condiciones de emplazamiento y accesibilidad, se caracteriza por concentrar gran parte de la población y de los servicios, lo cual hace que este sector de la parroquia posea características urbanas y por ende una actividad económica con mayor diversidad, la dinámica es mayor con respecto a las interacciones e intercambio con centros poblados de mayor jerarquía aledaños a la parroquia.

Los centros poblados están distribuidos de forma dispersa, localizados por lo general en fondos de valles intramontanos, línea de costa y paralelos a las principales vías de comunicación, Carayaca constituye el centro poblado que concentra la oferta de servicios y flujos comerciales. Así pues, el crecimiento urbano ha ocasionado el aumento de zonas con condiciones precarias, observándose ranchos y viviendas en mal estado que han surgido de manera espontánea sin ningún tipo de planificación y en algunos casos producto de invasiones.

En relación con la configuración del territorio está vinculada a los sistemas agrícolas consolidados en la parroquia Carayaca desde la época agroexportadora de Venezuela, la actividad agrícola, principalmente hortícola fue creciendo progresivamente, configurándose la red vial actual consistente en su mayor parte de vialidad agrícola y caminos de penetración, estas vías locales y ramales agrícolas, han constituido las columnas vertebrales en las que se ha apoyado las transformaciones de la organización territorial de la parroquia, ya que, permiten comunicar áreas agrícolas dispersas por la accidentada topografía de la parroquia con los principales centros poblados de la misma, observándose una concentración de la red vial en la sección este de la parroquia.

Así mismo, el sistema de ramales y vialidad agrícola que conecta áreas rurales y centros poblados con las vías locales, vencen las dificultades que imponen las condiciones topográficas en las áreas montañosas y agregan un significativo impacto en la economía, al impulsar y dinamizar el comercio. Sin embargo, ha generado el avance de la frontera agrícola hacia zonas bajo régimen de administración especial, afectando áreas de frágiles ecosistemas y de gran biodiversidad al establecerse usos no conformes con lo establecido en la normativa vigente. 


\section{Resultados y discusión}

\section{Conflictos Normativos}

\section{Zona Protectora del Área Metropolitana de Caracas}

Para el análisis de esta ABRAE se consideró el Plan de Ordenación y Reglamento de Uso de la Zona Protectora del Área Metropolitana de Caracas (1992), en el cual se constató que a pesar que existen dos unidades de ordenamiento, se evidencia incumplimiento del instrumento de ordenación debido a la existencia de usos no conformes. En la unidad de ordenamiento 10, correspondiente a la cuenca del río Petaquire, se pudo identificar que los sectores Las Lapas, Río Arriba y cuenca de la quebrada El Hondón, están siendo utilizadas para la actividad agrícola sin prácticas conservacionistas, no cumpliendo así con los artículos 19 y 23 de dicho reglamento.

Mientras que, el artículo 23 establece que en los suelos con pendientes entre 30$45 \%$ se permiten los cultivos permanentes, y tampoco se cumple debido a que se constataron áreas con cultivos hortícolas y sin prácticas conservacionistas en pendientes superiores a 30\% en los sectores El Hondón, Río Arriba, Alto Lagunazo y Media Legua; incumpliendo también lo consagrado en el artículo 27, en donde se establece que en pendientes $>30 \%$ se prohíbe los cultivos anuales y semipermanentes.

Ahora bien, de conformidad con el artículo 41 en la cuenca del río Petaquire solo se permite el uso de protección, agrícola conservacionista forestal y recreación; no obstante a través de las vistas a campo se pudo constatar que dicha cuenca está altamente intervenida sobre todo con cultivos hortícolas. Además, se observa en la cuenca cultivos anuales y semipermanentes en áreas con pendientes superiores a $45 \%$.

En la unidad de ordenamiento 11, se evidencian conflictos en los usos protector, agrícola y residencial, ya que el artículo 22 establece que las instalaciones deben ubicarse fuera de zonas protectoras de cuerpos de agua, y en las microcuencas Pericoco, Tibroncito, Yagrumal, se evidencia el establecimiento de actividad agrícola dentro del área definida según la Ley de Aguas como zona protectora de cuerpos de agua.

Por otra parte, el uso residencial debe estar fuera de las zonas protectoras establecidas por la Ley de Aguas y en áreas con pendientes menor o igual a 30\%, dicha norma no se cumple, debido a que existen zonas que están siendo destinadas para uso residencial dentro de los 300 m establecidos por la Ley de Aguas (artículo 54), igualmente se evidencian construcciones en pendientes superiores al 30\% en las quebradas Pericoco, Tibroncito, Yagrumal y El Tigre.

Asimismo, en el reglamento se establece que la construcción para el uso residencial debe tener una densidad mínima de 20 hab/ha, llama la atención que no se cumple y se evidencia claramente con la formulación y ejecución de proyectos habitacionales de gran envergadura promovidos por el Estado, como lo es la creación de Ciudad Caribia que contempla la construcción de 20000 apartamentos para 100000 habitantes, por lo que afecta de manera directa la Zona Protectora, la poligonal de éste desarrollo está dentro de la unidad de ordenamiento 11. 


\section{Monumento Natural Pico Codazzi}

A pesar que la figura tiene más de dos décadas de haber sido creada no posee plan de ordenación ni reglamento de uso, sin embargo las actividades se rigen por lo establecido en el Decreto $N^{\circ}$ 276, correspondiente al Reglamento Parcial de la Ley Orgánica para la Ordenación del Territorio sobre Administración y Manejo de Parques Nacionales y Monumentos Naturales (1989).

$\mathrm{Al}$ analizar dicho reglamento, se evidencian incumplimiento de la normativa y actividades incompatibles con el monumento, en primer lugar no se cumple con los parágrafos 1 y 11 del artículo 16 en los que se prohíben actividades agrícolas y la construcción de establecimientos humanos en monumentos naturales, al contrario, se han fomentado y aunque dichas actividades se presentan de manera dispersa, se evidencia establecimientos agrícolas en los sectores Alto Lagunazo, Buenos Aires y en la naciente del río Limón, que tienen un efecto negativo en el monumento, debido a que se constataron en estas localidades cultivos hortícolas principalmente.

Por otra parte, el reglamento en su artículo 19 numeral 4, establece que se prohíbe el vertido de contaminantes de cualquier tipo a los cursos de agua, y dadas las condiciones existentes en los centros poblados dentro del monumento, no existe un sistema de recolección de aguas servidas, ni de recolección de basura que cubra toda la parroquia y que garantice la correcta disposición final de los mismos. Con la lamentable consecuencia del vertido de desechos sólidos dentro del monumento.

A pesar de que en dicho reglamento se establecen las normas por las cuales se rige la administración y manejo de los monumentos naturales, las mismas son muy generales, razón por la cual se requiere de lineamientos más específicos como lo son los planes de ordenación y sus respectivos reglamentos de uso, que se adapten a las necesidades y realidad del Monumento Natural Pico Codazzi y se consoliden en un instrumento de acuerdo a lo estipulado en la ley.

\section{Zona de Utilidad Pública y de Interés Turístico Recreacional}

Esta figura ABRAE, no posee plan de ordenación ni reglamento de uso que regule las actividades que allí se desarrollan, a pesar de haber sido creada hace más de cuatro décadas. Por ello, la figura se administra según lo establecido en el Decreto con Fuerza de Ley de Zonas Costeras (2001). En el Título III de dicho decreto, se establece de forma taxativa las actividades que quedan restringidas en el dominio público de la franja terrestre de las zonas costeras, así como también las prohibidas, no obstante, dicha ley no posee un reglamento por el cual se rijan las directrices establecidas, en consecuencia los lineamientos son muy generales. Por otra parte, tanto el Ministerio de Turismo (MINTUR) como el Instituto Socialista de la Pesca y Acuicultura (INSOPESCA) tienen injerencia, MINTUR para la otorgación de ocupación del territorio e INSOPESCA por la Ley de Marinas y Actividades Conexas. 


\section{Zona Protectora de los Cuerpos de Agua}

Según el artículo 53 de la Ley de Aguas 2007, las zonas protectoras de los cuerpos de agua constituyen ABRAE para la gestión integral de las aguas; y en el artículo 54 numeral 2, se establece como zona protectora una franja de $300 \mathrm{~m}$, a ambas márgenes de los ríos. Al realizar el análisis del buffer creado a partir de los cuerpos de agua y los $300 \mathrm{~m}$ decretados según la ley, se observa el establecimiento de la actividad agrícola dentro del mismo, las áreas donde se evidencia esta actividad corresponde a las cuencas altas y medias de los ríos Limón, Chichiriviche, Oricao y Petaquire principalmente.

El hecho que la zona protectora este siendo ocupada por la actividad agrícola contraviene lo señalado en el artículo 54 de la Ley de Aguas, en donde se establece que dichas zonas: "tendrán como objetivo fundamental proteger áreas sensibles de las cuales depende la permanencia y calidad del recurso...”, y al desarrollarse ésta actividad en la parte alta de las cuencas compromete la calidad del recurso aguas abajo, sobre todo por el vertido de contaminantes en los cursos de agua y en especial el uso de fertilizantes indispensables para los cultivos.

En síntesis, al analizar los lineamientos existentes para las ABRAE se observa que las estrategias de conservación y protección restringen las actividades agrícolas, pecuarias y residenciales principalmente. Sin embargo, dichas estrategias se quedan solo en los decretos y documentos técnicos, puesto que se declaran pero no se implementan, evidenciándose en algunos casos incumplimiento de las mismas y por ende el establecimiento de usos no conformes con lo establecido en la legislación actual, y en otros casos, vacíos jurídicos por la inexistencia de normativas específicas que regulen las actividades particulares compatibles con las figuras administrativas.

\section{Conflictos por pendiente}

Tanto en las ABRAE como el resto de la parroquia existe una fuerte restricción por la pendiente, más del $65 \%$ de la parroquia posee pendientes superiores a $40 \%$, lo cual limita el desarrollo de actividades. Sin embargo, se observa el establecimiento de la actividad agrícola y asentamientos poblacionales en lugares no aptos y no permitidos para la misma.

Al realizar el análisis de la pendiente y la normativa de suelos establecida en la Ley de Forestal de Suelos y de Aguas, y el Reglamento de la Ley de Forestal de Suelos y Aguas, correspondiente a la utilización agrícola de los suelos, se observa incumplimiento del mismo, considerando que para las pendientes entre 15 y 35\% según el artículo 175 se permiten cultivos limpios, anuales o semipermanentes; siempre y cuando se haga uso de prácticas conservacionistas que controlen la erosión. En la zona se evidencian cultivos frutales y hortícolas (brócoli, 
repollo, cilantro, coliflor calabacín, ajo porro, lechuga y acelga), estos últimos sin prácticas conservacionistas, en algunos casos, en pendientes superiores a 15\% en los sectores Las Lapas, Río Arriba, Arbolito, El Hondón, El Tigre, Alto Lagunazo, Media Legua y Tibroncito. De igual manera, encontramos cultivos hortícolas en suelos con pendientes superiores a $35 \%$ en los sectores antes mencionados; y tampoco se cumple con el artículo 176, que establece para pendientes entre 35 y $50 \%$ el uso apropiados son cultivos permanentes como café y frutales, implementando prácticas conservacionistas.

Además de ello, según lo señalado en el artículo 178, en pendientes superiores a 35\% no se podrán establecer cultivos erosivos, evidentemente esto no se cumple. Las zonas con mayor conflicto por pendiente corresponden a las cuencas altas y medias de los ríos Chichiriviche, Petaquire y Oricao principalmente.

Igualmente, según el parágrafo segundo del título IX del Reglamento, las áreas con pendientes medias superiores a 35\% quedan excluidas de la actividad agropecuaria, no obstante, se identificaron áreas con actividad agropecuaria en pendientes superiores al 35\% en el sector Tibroncito.

De acuerdo a las restricciones por pendiente, y atendiendo a las consideraciones establecidas en la normativa, se puede afirmar que dentro de la parroquia la superficie que ofrece potencialidades para la actividad agrícola es muy baja, aproximadamente un $25 \%$ de la superficie total, siempre y cuando se haga uso de prácticas conservacionistas. Por su parte, el resto de la superficie de la parroquia presenta pendientes fuertes que son propensas a sufrir procesos erosivos, razón por la cual, deben estar sujetas a medidas conservacionistas considerando que es en estas zonas donde se ubican las nacientes de los principales ríos de la parroquia.

\section{Conflictos por erosión}

En Venezuela la agricultura sobre pendientes superiores al 10 o 15\% ha dado como resultado una fuerte erosión y la perdida de suelos valiosos. Sin embargo, estos problemas erosivos no son el producto de la ineptitud de los suelos para ser cultivados, sino el resultado de malas prácticas agrícolas (Sistemas Ambientales Venezolanos, 1982). La parroquia Carayaca no escapa a esta realidad, caracterizada por ser un área agrícola con pendientes restrictivas para dicha actividad, especialmente para el tipo de cultivo limpios, como los hortícolas, dadas las elevadas tasas de erosión a que están propensos los suelos.

En este contexto, se realizó un análisis de las áreas con mayor riesgo de erosión en la parroquia considerando la pendiente del terreno y la proximidad de los ríos correspondiente con la zona protectora de los cuerpos de agua establecida en el artículo 54 de la Ley de Aguas. Como resultado del análisis, se identificaron las zonas susceptibles a erosión, las cuales ocupan un superficie de 12 104,49 ha, lo 
que representa un $25 \%$ de la parroquia y se localizan principalmente en la cuenca alta del río Oricao, Petaquire y Limón, en dichas cuencas se evidencia la existencia de cultivos hortícolas dentro de la zona protectora de los cuerpos de agua.

Dicha situación es preocupante, considerando la investigación llevada a cabo por Fernández (1994), en la estación experimental Bajo Seco ubicada dentro del área de estudio en la cuenca del río Petaquire, esta investigación determinó que las pérdidas de suelo son mayores en los usos hortícolas que en los suelos bajo usos permanentes, y ello se explica por la mayor consolidación del suelo y cobertura a ras del suelo que proporcionan los cultivos permanentes. Asimismo, asevera que el uso del suelo homogeniza el comportamiento de este ante la erosión, los suelos bajo un mismo tipo de uso tienden a parecerse debido a ciertas características que adquieren por el tipo de utilización, a consecuencia de la incorporación de materia orgánica y el grado de mecanización.

La afirmación anterior explica que en suelos donde el tipo de uso requiere alterar periódicamente las condiciones superficiales por medio de la mecanización, el volumen de materia orgánica a incorporarse al suelo es muy bajo; por tanto la erosión tiende a ser mayor, tal es el caso de los cultivos hortícolas en las cuencas altas de la parroquia Carayaca.

Por otra parte, al evaluar el Reglamento de la Ley de Suelos en su artículo 178 señala que en pendientes mayores a 35\% no podrán ser aprovechados para el establecimiento de cultivos erosivos, sin embargo, se constató que en estas pendientes se han establecido cultivos hortícolas que son altamente erosivos, al mismo tiempo que se ubican en las zonas determinadas por el presente estudio como susceptibles a erosión.

\section{Análisis de los conflitos}

Existe en la parroquia un total de 20332,82 ha con conflicto de uso, que representa aproximadamente un $43 \%$ del total de la parroquia (Tabla 1). El conflicto que tiene mayor proporción es el conflicto por pendiente (Figura 2); esto es explicado por las condiciones topográficas de la parroquia, caracterizada por presentar un relieve abrupto donde aproximadamente $82 \%$ de la superficie posee pendientes superiores a $35 \%$. A pesar de esta restricción y escasas áreas para el aprovechamiento, esto no ha sido una limitación para el desarrollo de la actividad agrícola principalmente, al igual que tampoco ha sido una limitación la existencia de reglamentos que establecen como prioridad el uso conservacionista de estas áreas, dada la susceptibilidad a procesos erosivos y fragilidad de los ecosistemas.

Por otra parte, el conflicto en las ABRAE está presente aunque en menor proporción que el conflicto por pendiente. Sin embargo, por las condiciones físicas, gran 
Tabla 1

Superficie de conflitos

\begin{tabular}{lrr}
\hline Tipo & Área (ha) & \multicolumn{1}{c}{$\%$} \\
\hline Conflicto en pendiente $>40 \%$ & 8386.48 & 17.59 \\
Conflicto en ABRAE & 4052.86 & 8.50 \\
Conflicto en ABRAE y pendiente $>40 \%$ & 7893.48 & 16.55 \\
Conflicto en la parroquia Carayaca & 20332.82 & 42.63 \\
\hline
\end{tabular}

Fuente: elaboración propia.

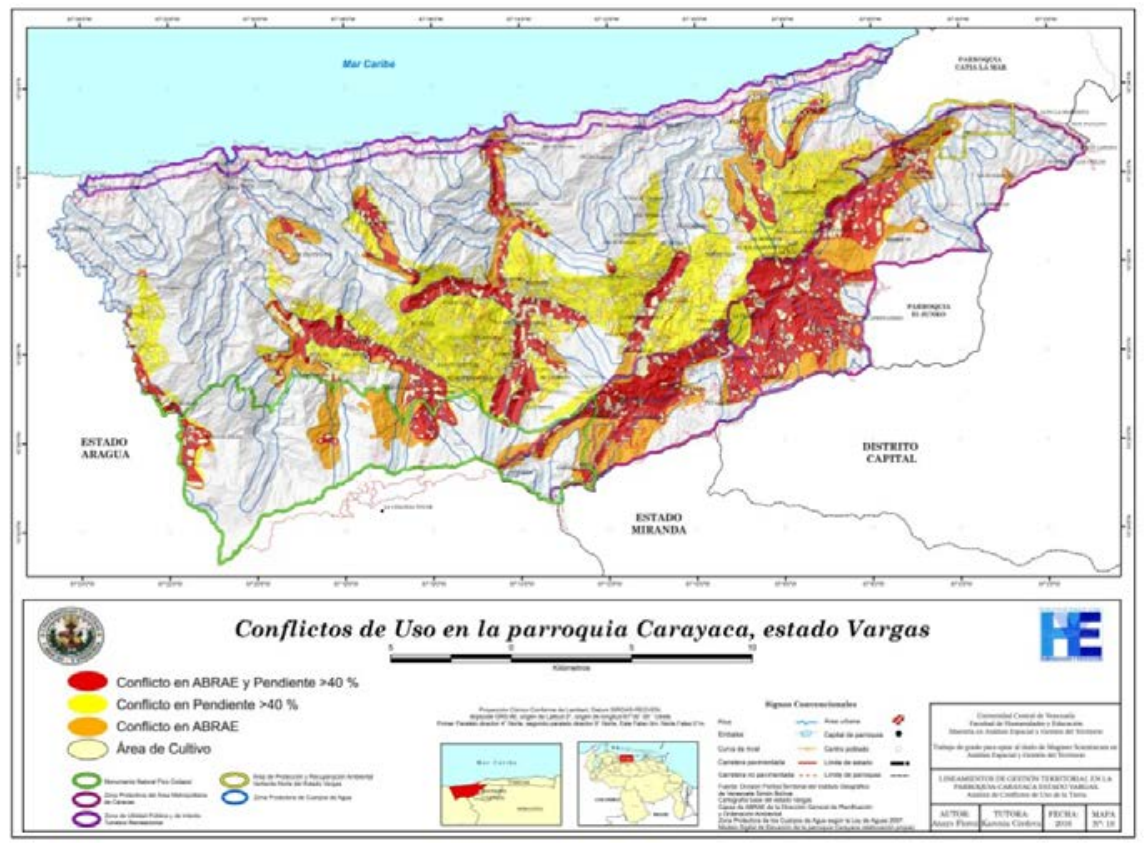

Figura 2. Conflictos de uso

biodiversidad y endemismo de las especies características de la parroquia, las cuales han sido motivos para su declaración como figuras administrativas, hacen que las abrae tengan gran importancia ecológica para la parroquia. Por esta razón, las actividades que allí se desarrollan deben tener armonía con los objetivos de conservación para las cuales fueron creadas; es de gran preocupación, pues evidentemente no se están cumpliendo, lo cual pone en riesgo la preservación de las especies.

De igual manera, considerando la importancia de las ABRAE en la parroquia, que ocupan aproximadamente $61 \%$ de la superficie, de las cuales $25 \%$ fueron determi- 
nadas en la presente investigación como áreas de conflicto en ABRAE, es decir que el $41.1 \%$ de las figuras bajo administración especial poseen conflicto. El área identificada con conflicto tanto por pendiente como por ABRAE ocupa el $17 \%$ de la parroquia.

\section{Propuestas de uso y manejo de los recursos de la parroquia Carayaca}

Una vez realizado el análisis de las condiciones fisiconaturales, socioeconómicas, políticas y normativas de la parroquia Carayaca, fue posible determinar los conflictos existentes derivados de la dinámica socioterritorial, en función de ello se establecieron algunos lineamientos de acción con base de ordenación territorial:

- Elaborar los Planes de Ordenación y Reglamento de Uso para las áreas que no cuentan con dicho instrumento, revisar evaluar y actualizar el Plan de Ordenación y Reglamento de Uso de la Zona Protectora del Área Metropolitana de Caracas, la institución que tiene competencia para ello es el Instituto Nacional de Parques (INPARQUES).

- Revisar y evaluar el solapamiento de las ABRAE para atenuar conflictos de uso y de competencia, a fin de sincerar espacios actualmente ocupados por usos no conformes, lo cual le corresponde al INPARQUES.

- Creación de un catastro rural, que permita conocer la vocación de uso de la tierra de cada unidad de producción, de manera de monitorear la conformidad de usos de la tierra. Siendo un insumo valioso para la contribución a la definición usos conformes, capacidad de carga de ecosistemas, recuperación y resiliencia, etc. La Alcaldía debe abocarse a ello apoyándose en instituciones como el Instituto Geográfico de Venezuela Simón Bolívar (IGVSB) y el Instituto Nacional de Tierras (INTI).

- Dadas los fuertes y continuos procesos erosivos a que están propensos los suelos de la parroquia en pendientes $>40 \%$, no deben establecerse cultivos hortícolas en estas áreas; solo se debe permitir el uso agrícola de cultivos permanentes con prácticas conservacionistas que controlen la erosión, pues la mayor parte de la parroquia posee fuertes pendientes y son propensas a sufrir procesos erosivos.

- Deben prohibirse los cultivos en las zonas protectoras de los cuerpos de agua y de esta manera cumplir con lo establecido en la Ley de Aguas.

- Se debe exhortar a las autoridades a no permitir desarrollos urbanísticos de gran envergadura en zonas frágiles y exigir por parte del Ministerio del Poder Popular para Ecosocialismo y Aguas (MINEA) la elaboración de estudios de impacto ambiental para determinar la viabilidad de los proyectos.

- Realización de estudios detallados relacionados con: las propiedades y capacidades agroecológicas del área para determinar usos de la tierra compatibles y potenciales, tasas de erosión, arrastre y acarreo de sedimentos, movimientos en masa y procesos 
hidrogeomorfológicos acentuados para determinar grado de vulnerabilidad ecológica y amenazas y riesgos a la población, etc. Tanto INTI como el Instituto Nacional de Desarrollo Rural (INDER) pueden propiciar la realización de dichos estudios, de igual manera instituciones de investigación y universidades constituyen actores fundamentales.

- Desarrollo de programas de reforestación en las partes altas de las cuencas con fines conservacionista, manejo integral de ecosistemas y uso sostenido del recurso agua, por medio del apoyo de MINEA en la parroquia.

\section{Conclusión}

Partiendo de la revisión bibliográfica y electrónica realizada en la investigación para conformar los principales lineamientos teórico referenciales, se puede afirmar que la mayoría de los estudios publicados realizan la identificación de conflictos de uso de la tierra por medio de cambios en la cobertura para dos o más momentos, y mediante la confrontación de los usos actuales con el uso potencial; mientras que muy pocas consideran los conflictos normativos en las abrae. Sin embargo, no se realiza un análisis exhaustivo del basamento legal para determinar dicho conflicto. En este particular, con la metodología empleada se logró analizar de manera detallada los conflictos normativos derivados de la aplicación de regulaciones frente a la problemática de ocupación de las abrae y la legislación sobre suelos, dejando en evidencia las inconsistencias, contradicciones y vacíos jurídicos por la cual se rigen las áreas protegidas de la parroquia. Este análisis constituye uno de los principales aportes de la investigación.

Adicionalmente, se destaca la importancia de la integración entre las técnicas de procesamiento digital de imágenes de satélite con el análisis espacial de la información temática para la identificación, análisis y cuantificación de los conflictos de uso de la tierra. Fundamentalmente por la utilidad de poder visualizar un área de gran extensión territorial, como lo es la parroquia Carayaca en una sola imagen, y a partir de allí poder diferenciar las categorías de uso y otras variables que interactúan en la configuración actual del territorio. Mediante la interpretación de la imagen LANDSAT 8-OLI, se logró cuantificar los conflictos en la parroquia Carayaca. Sin embargo, para identificar áreas agrícolas de menor dimensión que no se logran detectar por el sensor LANDSAT, es necesario realizar estudios de campo sobre localidades específicas o trabajar imágenes de mayor resolución espacial, a fin de identificar el impacto de las pequeñas parcelas sobre los conflictos de uso en la parroquia.

Considerando la importancia de las condiciones físicas, la gran biodiversidad y el endemismo de especies que han propiciado la declaración de ABRAE en la parroquia, es imprescindible que las actividades que se desarrollen sean cónsonas con los objetivos de conservación para los cuales fueron creadas, y es de gran preocupa- 
ción que exista conflicto normativo en las ABRAE. Igualmente, es necesario identificar los actores implicados en el proceso de ordenación del territorio, definir los instrumentos de participación y diseñar canales apropiados para lograr la coordinación entre los organismos ejecutores de obras físicas, las comunidades y los entes administradores de recursos; para que tomen como base las propuestas de uso y manejo derivadas de la presente investigación, a fin de diseñar lineamientos estratégicos y acciones de programación enmarcadas dentro del proceso de gestión para la ordenación del territorio de esta importante área agrícola.

\section{Bibliografía}

Fernández, L., (1994). "Evaluación del riesgo de erosión por salpique en suelos de la cuenca alta del rio Petaquire”, Caracas: Palmaven, Venezuela, 2 (2).

Ministerio del Ambiente y de los Recursos Naturales Renovables (MARNR), (1985). "Esquema de Ordenamiento Territorial de la parroquia Carayaca”, Dirección General Sectorial de Planificación y Ordenación del Ambiente, Caracas.

Ministerio del Poder Popular para el Ambiente (MPPA), (2011). "Diagnóstico Integral de las Cuencas Hidrográficas Petaquire y Oricao de la Parroquia Carayaca, Estado Vargas", Caracas.

República de Venezuela, (1966). Ley Forestal de Suelos y Aguas, Gaceta Oficial núm 1 004, Extraordinario de fecha 26 de enero de 1966.

República de Venezuela, (1977). Decreto № 2117, Gaceta Oficial núm 2022, Extraordinario de fecha 28 de abril de 1977, mediante el cual se crea el Reglamento de la Ley Forestal de Suelos y de Aguas.

República de Venezuela, (1989). Decreto Nº 276, Gaceta Oficial núm. 4 106, Extraordinario de fecha 9 de junio de 1989, mediante el cual se crea el Reglamento Parcial de la Ley Orgánica para la Ordenación del Territorio sobre Administración y Manejo de Parques Nacionales y Monumentos Naturales.

República de Venezuela, (1992). Decreto 2299, Gaceta Oficial núm 35133, fecha 18 de enero de 1993, mediante el que se crea el Plan de Ordenación y Reglamento de Uso de la Zona Protectora del Área Metropolitana de Caracas.

República Bolivariana de Venezuela, (2001). Decreto ํ1468, Gaceta Oficial núm. 37349 de fecha 19 de diciembre de 2001, mediante el cual se crea el Decreto con Fuerza de Ley de Zonas Costeras.

República Bolivariana de Venezuela, (2007). Ley de Aguas, Gaceta Oficial núm. 38 595, de fecha 2 de enero de 2007.

Sistemas Ambientales Venezolanos, (1982). "Los problemas ambientales de Venezuela”, Proyecto VEN/79/001, serie III documento $N^{\circ} 6.223$ pp. 